\title{
Forming communities of practice
}

\section{Christine Keenan}

Bournemouth University, UK

\section{Arti Kumar}

University of Bedfordshire, UK

\section{Peter Hughes}

University of Bradford, UK

\section{Abstract}

The National Action Research Network (NARN) on Researching and Evaluating Personal Development Planning (PDP) and e-Portfolio was funded through the Higher Education Academy National Teaching Fellowship Scheme in 2007. It brought together a partnership of people from 16 English Higher Education Institutions (HEIs) who were already members of national PDP networks - most significantly the Centre for Recording Achievement. The broader project aim was to develop research capacity among PDP practitioners and in order to help keep this aim manageable, smaller groups based on regional groupings were set up. Although the membership did come together to share experiences at national events, it was thought that the smaller groups would be more manageable units for the more concentrated work of setting up local research projects. Each group member came with an idea for a research project, many of which are exemplified in this special edition, and over the course of the three years regional groups met to review, feedback and build on the research they had been undertaking. This brief article describes the experiences of the three regional groups and concludes that there are a number of characteristics that contribute to the success of a community of practice, including notions of joint enterprise, shared repertoire and mutual engagement, but success in achieving these relies on shared commitments and the development of trust and respect amongst the group members.

Key words: communities of practice; regional groups; team working; research. 


\section{Introduction}

Communities of practice can develop when a group of like-minded people come together informally to share common interests. An example of this might be the coming together of practitioners within the Learning Development in Higher Education community, an informal grouping of people who share a vision and passion for empowering student learning. They can also be formed more formally for a particular purpose, for example, the NTFS NARN project which is the subject of this case study. In this example, a network of people who were already involved in national personal development planning networks were brought together to develop and share their knowledge and experience. According to Lave and Wenger (1991) it is through the sharing of information, experiences and practice that members learn from each other and develop themselves personally and professionally. According to Wenger (1998) a community of practice is constituted of people who have a passion for what they do and through interactions with others can improve their practice. For Lave and Wenger a community of practice has three important features: firstly the domain, which in the NTFS NARN example is Personal Development Planning (PDP); secondly, the community and finally, the practice. Our community was drawn from an existing grouping of practitioners who all share a passion for PDP and are all members of the Centre for Recording Achievement. The three year NTFS NARN project was designed to be an action research network structured through three regional groupings. These smaller groupings within the overall project provided a space within which members could explore, share experiences and progress, develop themselves personally and professionally and, most importantly, act as critical friends to each other. By briefly reviewing their experiences it is possible to draw out some of the features of successful communities of practice.

The overall aim of the NTFS NARN project was to develop research capacity within the UK PDP community. The deliberate regional grouping of partners (south, midlands and north) was helpful as it made regular face-to-face meetings more feasible and six scheduled regional meetings were held during the three years of the project. The meetings were designed to mirror the project research cycle. The sequence of meetings was:

- Trust building and sharing issues.

- Defining research questions.

- Sharing and discussion about gathering data. 
- Sharing and discussion about analysing data.

- Discussion of research findings and recommendations.

- Dissemination strategies.

\section{The Southern Region experience - led by Christine Keenan}

The southern region bonded into an effective community of practice very quickly. Members came from Universities in Kent, Canterbury, Portsmouth, Exeter and Bournemouth and brought a wide range of strengths and experiences with them to the project. A significant feature of this group was its membership stability: there were no changes in institutional or individual membership during the life span of the three year project. The group membership was all female. A key factor for the southern region was that most members already knew each other, which facilitated rapid bonding. It is difficult to know whether gender was in itself a significant factor in the bonding process that led to a very successful group, or whether it was something to do with the combination of circumstances which were stable membership, existing strong relationships and shared core values that seems to define how our very effective strong community of practice evolved so quickly. An important further characteristic of this group was the highly developed sense of mutual support and shared endeavour that came through the first discussions. This speedily set the scene and atmosphere around the exploration of new ideas and provided a safe space for the articulation of any doubts, concerns or worries that emerged during the time of the project. Regular face to face meetings took place, and although the first meeting was held within an institutional context, subsequent meetings were held at the British Museum and the British Library in London. Initially this was done to ease travel difficulties across the width of the region but the change of scenery and atmosphere was very much valued by the members. The trips to London, the beautiful surroundings, the sense of occasion and special lunches added to the sense of occasion!

The southern team shared a common vision of the project goals which were to improve staff and student experiences of PDP. Our shared interest and collective enthusiasms formed the basis of our mutual learning. These shared interests and enthusiasms provided the underpinning of a sense of 'belonging to a community', our developing confidence in 'becoming' researchers, how understandings and meanings developed through our 
'experiences', and how we put our practice into 'doing' action, mirrored Wenger's 1998 model (Figure 1).

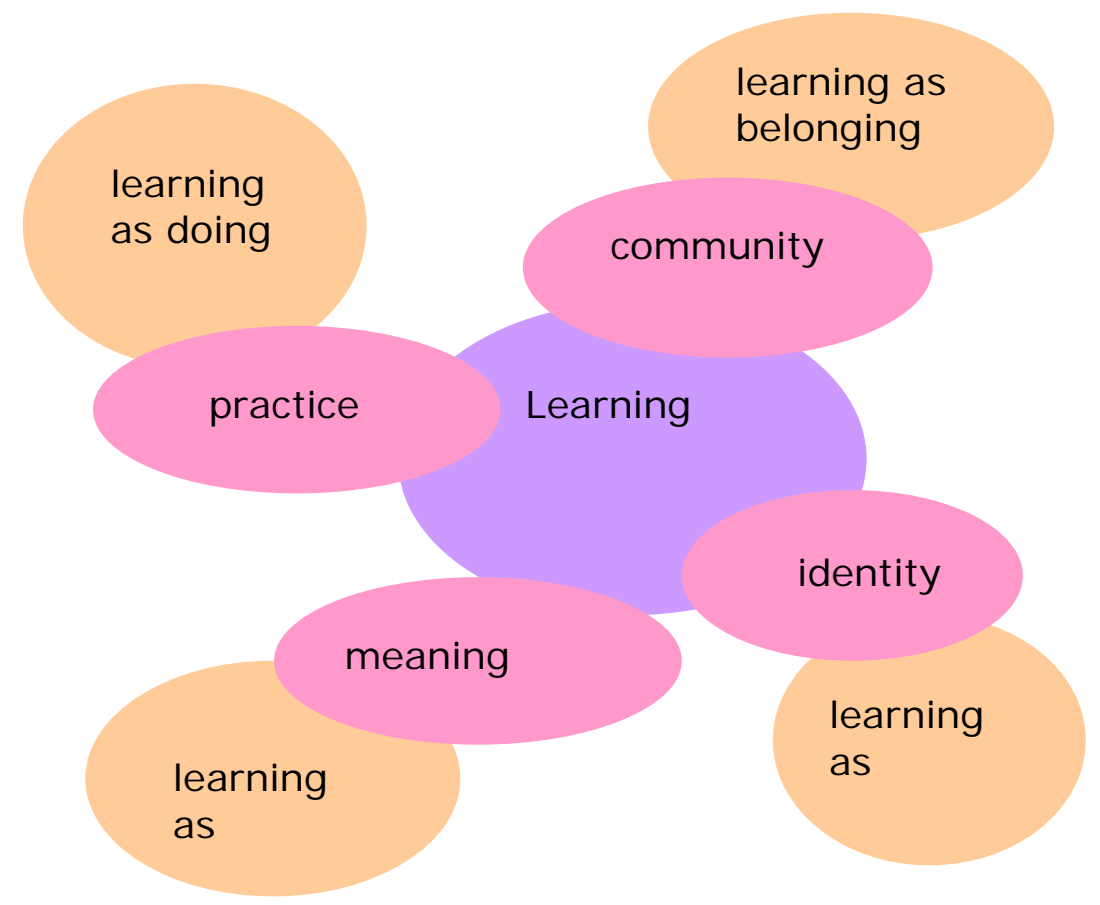

Figure 1. Wenger (1998, p.5).

The southern team took successful outcomes as a given. However, within the expectation of successful outcomes, the team developed an environment in which worries could be expressed, new ideas and approaches could be safely explored, and reassurance given when things went wrong. Criticality was also achieved. The group acted as critical friends, challenging each other, being critically evaluative, praising each other and learning from each other.

There are quantifiable measures of success. For example, deadlines were met and attendance was high at regional and national meetings. Exactly how success was achieved is less tangible. There were frequent communications including phone conversations and email discussions, and extra meetings were held when needed, for example, when one member had been unable to attend scheduled regional meetings other members got together and met with her separately to keep her up to speed. Success was also achieved by members working proactively on each other's behalf when pressures of other work were pressing. This was central to the members making effective personal contributions within the community of practice. 
It was hard work and sometimes traumatic. However, the team members got to know each other very well and had clear insights into each other's contexts and local stress points. The success of the group relied very much on the interplay between its members each playing their part in the identity building and maintenance of the group. This closeness helped the southern region members sustain each other through the hard times both emotionally with encouragement and practically with members picking up work for each other when times were difficult. There was also a lot of fun along the way which helped with the community maintenance that is so important in developing communities of practice.

\section{The Midlands Group experience - led by Arti Kumar}

The midlands region comprised membership from universities at Bedfordshire, Birmingham City, Coventry, Gloucester, Wolverhampton and Worcester. Again there was stability in the institutional membership with all six institutions and a core group of individuals staying with the project for its three year lifespan. However, in contrast to the southern region, over the course of the project about twenty further partners were drawn in, sometimes temporarily, sometimes as permanent substitutions. This led to different dynamics but the midland team maintained a sense of continuity of purpose throughout, though more in the sense of team building rather than community of practice development. During their first meeting, the team concentrated on getting to know each other, creating shared understandings and a common vision of the group's perception of the overall project goals and a vision of what might be realistically achieved. A graphic representation was used as a frame of reference for the discussions (Figure 2) to remind partners that team dynamics and processes are influenced by a variety of factors that in turn influence project management and project outcomes. The graphic provided a useful reflective resource to help partners look inwards as well as outwards - to consider how they reference themselves as individuals within the NARN project, how they are influenced by other teams to which they belong and in turn how these teams align (or misalign) with the demands of the university to which they belong. 


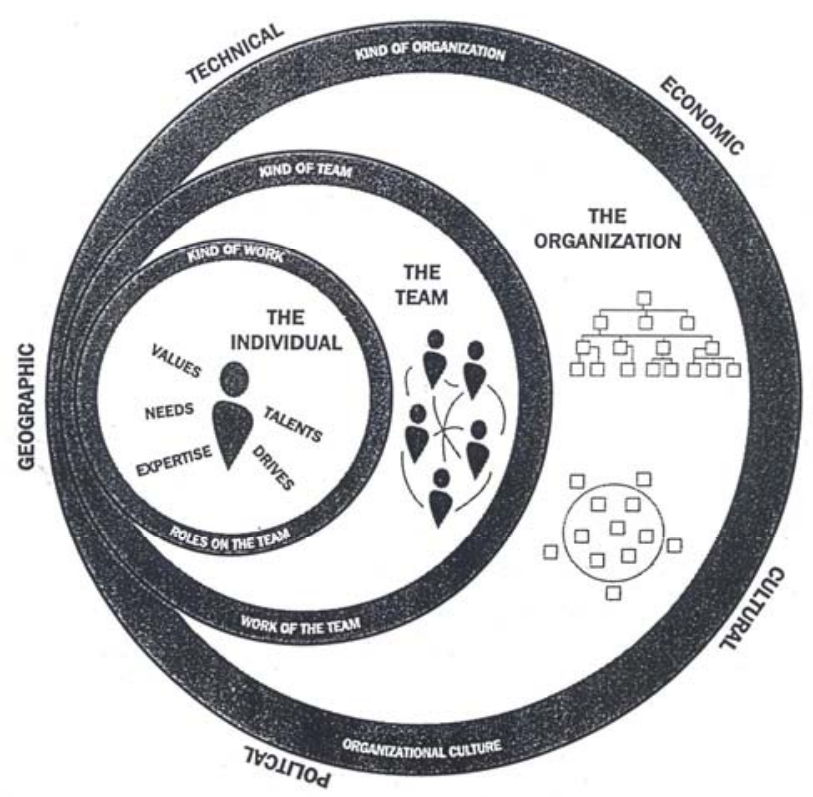

Figure 2. Berens et al., 2004.

Getting to know each other through expressing personal values, aspirations, needs, experiences and expertise that individuals within the team had in relation to a) PDP and/or e-Portfolio practice and b) research, was an important first step. This was very helpful in identifying the considerable diversity of perceptions, experience and confidence within the group in PDP practice and research. There was also much discussion about what was expected of the project members and about the complexity of the broader NARN project and how individuals within the team would develop in order to achieve their own project outcomes. The team looked at the overall project time frames and developed their own action plans, meeting plans and communication structures that would help it meet them.

The midlands group quickly realised that the team structures were highly complex. There were tensions sometimes in managing the complex mix of personal, institutional and national aspects of belonging to a national project that would influence members' ability to function as a team, let alone develop themselves as practitioner-researchers and writers. A key influence was in how individuals managed these interactions and the type of support received from line managers and colleagues with their respective institutions. As time went by, some of the members did receive less institutional support than others, and for others competing priorities meant they were unable to engage fully with NARN meetings. The cohesion and dynamics of the midlands group was also affected by its changing membership. The initial team-building efforts did not transfer to the subsequent members who joined - and the wider and looser groupings that resulted from the changes were not 
always conducive to creating shared values around a specific common PDP goal (this was indeed a problem that occurred to a greater or lesser extent in each of the regions).

Nevertheless, there was great individual enthusiasm around setting up projects and the core group worked hard together to ensure that ambitions were realistically feasible in the given timescales and work situations. The team also worked hard to overcome geographical difficulties, often coming together at Birmingham City as a most convenient meeting place. Towards the end of the project the team retreated together to a country house near Northampton as a quiet contemplative space for writing, discussion and relaxing. This was much appreciated by all!

\section{The Northern Group experience - led by Peter Hughes}

The university partners in the northern group were Bolton, Newcastle, Bradford, Salford and Central Lancashire. The experience of this group was characterised by an initial period of instability but this evolved into a mature community of critical friends.

The group experienced a number of pressures very early on in the process, mostly to do with fluidity and uncertainty in group membership, in terms of individuals representing institutions, rather than the institutions themselves. In only one of the institutions did the individual named in the initial project bid document remain as the key link person throughout the project. In a similar way to the midlands group there were often larger groupings involved within the individual institutions and this led to some uncertainly about group boundaries. As the initial period of the project was about trust building and group formation, the turnover of group members was initially unsettling. However, by the end of the first year a solid core membership had been reached, and the fact that occasionally different faces were at meetings was embraced as a positive feature: there was always an injection of fresh perspectives and new ideas.

A further characteristic of the group was the different academic backgrounds of the members, which included arts, social science and science. This enriched the discussion of research issues, as members were often operating according to very different epistemologies. Within the context of the group, this led to some genuine movement in 
people's perspectives and approaches to research, showing that the multi-disciplinary membership of the group led to inter-disciplinary learning.

A further thing to reflect on is the development of this group as a community of practice outside of institutional space. If educational development initiatives seek to develop communities of practice, then it makes sense that they adopt a community-based development approach (in contrast to individual or organisational-scale development) (Hughes, 2004) as Van Note Chism et al. (2002, p.38-39) note:

The CoP model...situates faculty development in a communal context. The tasks of faculty development, then, turn from an emphasis on individual change to promoting experimentation, inquiry and reflection in a collegial fashion.

The fact that these regional groupings were established outside of institutional context was found to liberate discussion and action from some of the practice situations that people encountered in their day-to-day settings.

Overall, the northern group developed into a CoP with a core group of people, but also had fluid boundaries that enabled other people to productively contribute and learn through 'legitimate peripheral participation' (Lave and Wenger, 1991). In practical terms, this saw the group support each other through a process which saw them move from an initial sharing of practice and perspectives on research, through identification of research questions and the conduct of research questions, before returning to enriched, evidenceinformed discussions of practice and research.

\section{What gives life to a community of practice?}

These brief descriptive accounts of the regional experiences reflect on their differing approaches, yet each demonstrates some common and fundamental characteristics of community of practice. The evolution of the three regional groups demonstrates strongly that each group was different. Each developed a unique sense of identity, each had its own ways of working and each managed its group relationships within the constraints they found themselves in. Yet, every participant bought into the idea of the regional group as a 
safe space for the development of ideas and it was often seen as a refreshing first step outside of a single institution perspective.

\section{The community voice}

During the final national meeting of the NARN project, members from all regions reflected on what made the regional teams work. A sense of community seems to arise where there is:

- A sense of shared enterprise.

- Voluntary membership.

- Selfless collaboration.

- Commitment to the success of the team.

- Collaboration, trust, respect.

- A safe place with critical friends.

- Friendship, shared experiences, stories.

- Validation of each other giving strength and value to individuals.

- Supportive leadership.

- Acceptance of different perspectives.

- Empathy.

- A sense of purpose.

- Strong communications. 
The southern region perspective of community of practice is represented in Figure 3:

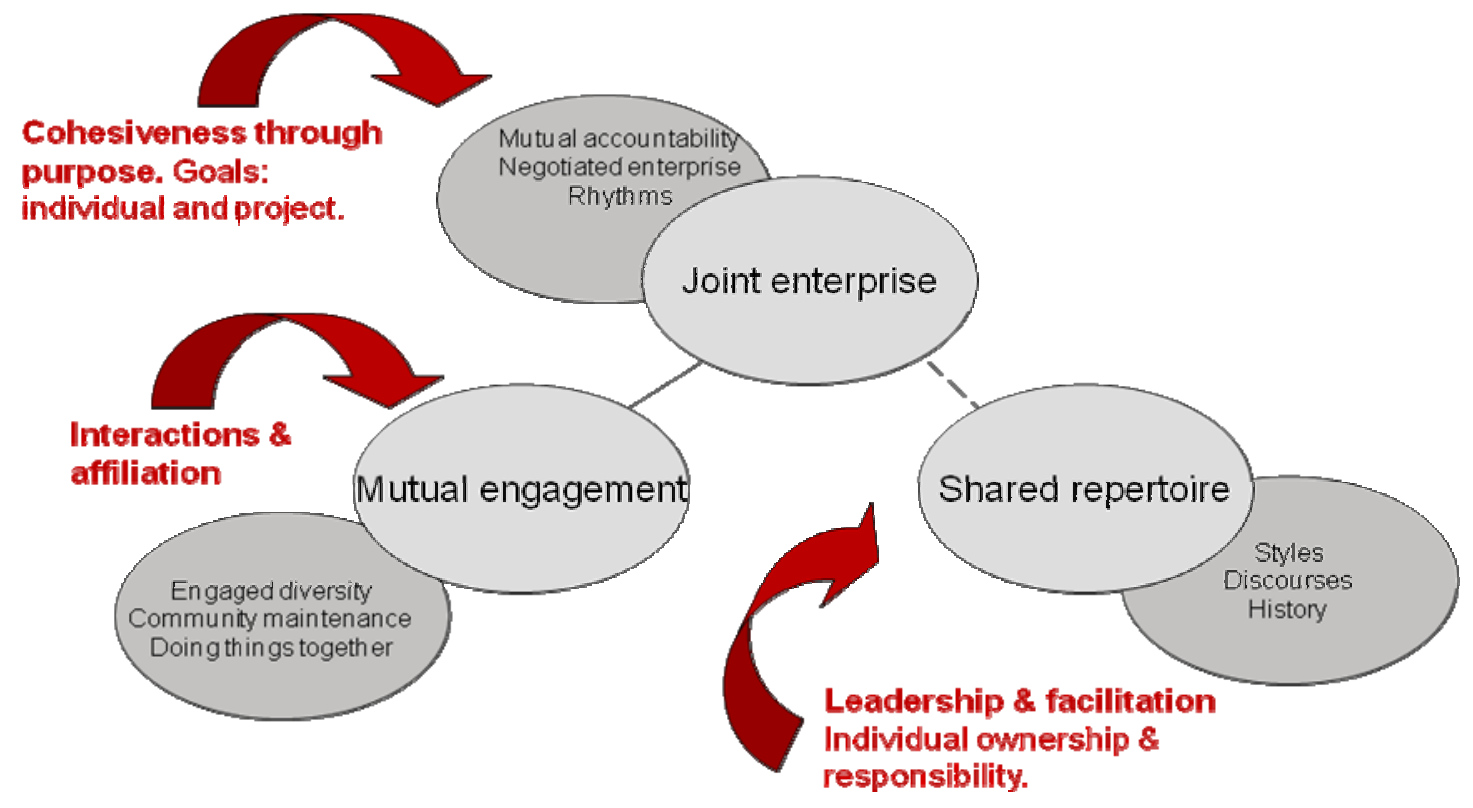

Figure 3. Model developed by members of the southern regional group (Buckley and Frith, 2010) based on Wenger (1998, p.72-73).

How this model worked in practice is articulated in the comments below:

\section{Joint enterprise:}

The group mostly met in London because of the difficulties of travel in the south region (everything goes via London). This decision proved very serendipitous as it meant that no one person was responsible for the logistics. It also gave everyone the same sense of being away from the office, no popping in and out for phone calls etc.

All of the accounting to the national group and various activities at the national level have been negotiated and different members of the group have taken responsibility for activities according to issues of time and expertise.

The rhythm of the regular regional meetings, national days and writing days has helped to keep momentum going. 
Shared repertoire:

The style of working has been non-intimidatory: although we all have different levels of experience and academic credentials, we all approached the project fresh. The tone was non-competitive and at times self-deprecating.

Although all our backgrounds and projects were different we did share a similar approach to PDP. We came from a 'PDP for learning' route and we all saw PDP as a potentially positive approach to help students make sense of their learning and transformation.

\section{Mutual engagement:}

All of our roles and projects were different but we needed the group to share ideas and sustain motivation.

The group was particularly good at community maintenance. The leader did a lot of work behind the scenes supporting members, and all members supported each other with ideas and solutions. All members of the group can identify a point at which they would have dropped out were it not for the efforts of the others in the group.

The space and time for a decent lunch was seen by all members of the group as a 'treat' and therefore contributed to positive feelings towards the group.

\section{In conclusion}

Whatever the theoretical and conceptual frameworks and underpinnings, projects such as this would not succeed without the commitment, engagement and enthusiasm of the people involved. The overall project aim of developing the research capacity of PDP practitioners was very dependent on the wholehearted willingness of all the partners to get involved and support each other. The sense of joint enterprise was built on individual ideas for institutional research projects and although the journey was not always a smooth one, it was through joint enterprise and mutual support that the individual projects achieved their 
aims in a rigorous way. The identity of the groups emerged through the notion of shared repertoire. Each of the regional groups had characteristics unique to them. The experience of meeting in the British Museum and the British Library added to the character of the southern region, and waiting for flights at Manchester airport will never be the same again for a number of reasons that always involved wine! The sense of mutual engagement shines through each of the descriptive regional accounts. The overall project achievements are greater than the sum of its parts and although the project has been completed it is clear that some friendships will continue.

The regional leads would like to thank all of the members for contributing so enthusiastically to the success of this NARN project. Particular thanks go to Carina Buckley, Louise Frith, Sue Riddell and Jane Rowe for permission to re-create their model and use their words!

\section{References}

Berens, L.V., Ernst, L. and Smith, M. (2004) Quick guide to the 16 personality types and teams: applying team essentials (TM) to create effective teams. Huntington Beach, CA: Telos Publications.

Buckley, C. and Frith, L. (2010) 'Building a PDP community of practice', CRA International Conference on PDP and e-portfolios. Nottingham 26-28 April.

Hughes, P. (2004) 'Community educational development for academic communities of practice', SEDA Spring Conference. Cardiff 29 March.

Lave, J. and Wenger, E. (1991) Situated learning: legitimate peripheral participation. Cambridge: Cambridge University Press.

Van Note Chism, N., Lees, N.D. and Evenbeck, S. (2002) 'Faculty development for teaching innovation', Liberal Education, 38 (3): pp. 34-41.

Wenger, E. (1998) Communities of practice: learning, meaning and identity. Cambridge: Cambridge University Press. 


\section{Author details}

Christine Keenan is a Learning and Teaching Fellow at Bournemouth University where she is involved in education and learning development within the School of Design, Engineering and Computing. Her research interest is around student transition and induction to HE. She is also a steering group member of the Association of Learning Development in Higher Education (ALDinHE).

Arti Kumar's work, as Associate Director of the Centre for Excellence in Teaching and Learning (CETL) at the University of Bedfordshire, has been central in the university's adoption of effective learner-centred pedagogies that connect personal and career development with good learning and employability approaches in higher education curricula. As part of her National Teaching Fellowship project (awarded in 2005) she authored the book entitled Personal, Academic and Career Development in Higher Education - SOARing to Success published in 2007 by Routledge Taylor \& Francis. She was awarded an MBE in the Queen's Honours list 2008 in recognition of her services to higher education. She is currently an Honorary Visiting Research Fellow at the University of Bedfordshire and also a Fellow of the National Institute of Career Education and Counselling (NICEC) and of the UK Higher Education Academy. She is an AGCAS Lifetime Achievement Award winner 2010.

Peter Hughes is Senior Lecturer in Learning Development within the Centre for Educational Development at the University of Bradford (p.hughes3@bradford.ac.uk). 